Research Article

\title{
Experimental Study on Flexural Properties of Side-Pressure Laminated Bamboo Beams
}

\author{
Jing Lei, Bowang Chen (iD, and Ping Yuan \\ Departments of Civil Engineering, Central South University of Forestry and Technology, Changsha 410004, Hunan, China \\ Correspondence should be addressed to Bowang Chen; 644746697@qq.com
}

Received 19 February 2020; Revised 21 May 2020; Accepted 23 May 2020; Published 15 June 2020

Academic Editor: Paolo Castaldo

Copyright (c 2020 Jing Lei et al. This is an open access article distributed under the Creative Commons Attribution License, which permits unrestricted use, distribution, and reproduction in any medium, provided the original work is properly cited.

\begin{abstract}
In this paper, two factors of width-to-height ratio and span-to-height ratio are considered and 10 side-pressure laminated bamboo beams are prepared and tested for flexural capacity to study the flexural performance when they are used as structural members. The failure mode, load-displacement curves, and the change rule of cross-section strain with height are obtained through the test. The results demonstrate that the side-pressure laminated bamboo beams have experienced elastic deformation stage, elasticplastic deformation stage, and failure stage; the midspan deflection of beams with considerable span-to-height ratio is too large to be applied to the ultimate load, and these specimens are regarded at the ultimate limit state; stiffness or deflection should be considered as the control index in the engineering application of the side-pressure laminated bamboo beams; the bearing capacity increases proportionately with the beam width; the average strain of the section basically conforms to the plane section assumption. The experiment proposes a method for calculating the flexural capacity of the side-pressure laminated bamboo beams with nonlinear deformation, and also, the comparison between the test value and the calculated value shows that they agree well.
\end{abstract}

\section{Introduction}

So far, the burgeoning of green buildings has become inevitable in eco-friendly and low-carbon sustainable development. As carbon-fixing renewable materials, bamboo and wood, with some characteristics such as easy decomposability, renewability, light mass, and high earthquake resistance, are ideal green construction materials [1]. Although bamboo is a promising green construction material, its application is limited by the diameter of the bamboo culm and the low rigidity [2].

Laminated bamboo (LB), as a relatively new type of bamboo composite fabricated by bamboo strips, can effectively tackle the problem that the crude bamboo member fails to meet the requirements of structural infrastructures for member cross-section dimension. Moreover, the strength and stiffness of LB composite are higher than those of bamboo; hence, it is an attractive alternative for traditional building materials and very suitable to use as columns, decks, and beams $[1,3]$. Because of its favorable mechanical properties and environmentally beneficial characteristics, LBL has been attracting numerous research studies [4-12].
Laminated bamboo lumber columns [1, 8-12], laminated bamboo hollow decks [3], and the effects of the layered structure, bamboo species, oil treatment, and glue type on the mechanical properties of laminated bamboo boarding have been investigated in the literature. [13-18].

Some research studies also have been conducted to investigate the bending capacity of laminated bamboo lumber. Wei et al. [19] examined the failure of laminated bamboo beams in detail and concluded that the cross-sectional stiffness was the control condition for design load. Sinha et al. [20], Lima Douglas Lima et al. [21], and Sharma et al. [22] examined the bending properties of LBL beams and reported considerable bending resistance that would benefit structural applications. Considering the two factors of shear-span ratio and height-to-width ratio, $\mathrm{Li}$ et al. [23] investigated the bending performance of the LBL beam with the full consideration of the size effect. Verma et al. [24] evaluated the mechanical properties of laminated bamboo composites (LBCs) under different loading conditions and introduced that LBCs can be used as an alternative to wood and wood-based composites for structural applications. In 2018, approaches of calculating for the ultimate 
bending moment and ultimate bending deflection were proposed by Li et al. [25] for three bending failure modes which gave a good agreement with the test results. According to a multitude of research studies, it is evident that LBL is a significant class of building structural material with good stiffness, small deformation, high strength, dimensional stability and wear resistance, and other advantages. And it has a bright application future.

However, the studies reported to date on the nonlinear characteristics of LBL are insufficient. As a contribution to this process, this paper investigates the mechanical properties of side-pressure LBL beams. And with the full consideration of the nonlinear deformation of the material under pressure, the calculation method of flexural bearing capacity is presented to provide a reference for engineering applications.

\section{Materials and Test Program}

2.1. Materials. Side-pressure laminated bamboo beams, supplied by Hunan Fenghe Bamboo Technology Co., Ltd., are made of excellent bamboo harvested over five years. Sidepressure laminated bamboo specimens are finally crafted through the production procedures such as screening, slitting, trimming, steaming, carbonizing, planing, gluing, assembling, and hot pressing. With the $6.3 \%$ ratio of measured moisture content and a density of $640 \mathrm{~kg} / \mathrm{m}^{3}$, experimental investigations indicate that the compressive yield strength and ultimate strength parallel to grain are $53 \mathrm{MPa}$ and $84.9 \mathrm{MPa}$, respectively. According to the tensile tests, the tensile strength for the laminated bamboo is $111.7 \mathrm{MPa}$, with a modulus of elasticity of 9194.4 MPa, and Poisson's ratio is 0.338 .

2.2. Specimen Design. Due to the lack of the current production reference and test methods of composite bamboo in China, this paper is in agreement with Testing methods of US reference ASTMD198-02 for timber beams [26] and GB/ T50329-2012 standard for test methods of timber structures [27]. This experiment concerns several factors such as height-towidth ratio, span-to-height ratio, and loading methods; accordingly, five groups of specimens are designed. And there are 2 side-pressure laminated bamboo beams in each group and a total of 10 side-pressure laminated bamboo beams. The height of the A, B, and C groups of specimens is $120 \mathrm{~mm}$, with the length of $2300 \mathrm{~mm}$ and effective span of $2040 \mathrm{~mm}$. As for the two groups (C and D), the height of the specimens is the same as that of the first three groups, while the length and effective span resize to $1150 \mathrm{~mm}$ and $1000 \mathrm{~mm}$, respectively. Table 1 shows the parameters of specimens.

2.3. Loading Scheme. The experiment is carried out in the structural experiment hall of the College of Civil Engineering, Central South University of Forestry and Technology. Each group of 2 specimens is prepared to undergo two different loading methods. $\mathrm{A}, \mathrm{B}$, and $\mathrm{C}$ are tested using a two-point monotonic loading configuration, as shown in Figure 1. And by using the one-point loading method, the bending tests of $\mathrm{D}$ and $\mathrm{E}$ are performed, as shown in Figure 2.
Prior to loading, this test preloads to $2 \mathrm{kN}$ and lasts for 2 minutes and then unloads at the same rate, which cycles twice in total. Preloading is used to bridge the gap between the loading device, the specimen, and the support, and also to check the sensitivity of the instrument and the firmness of the installation.

In order to obtain the change rule of midspan cross-section strain with height under the period of loading, five strain gauges are pasted in the midspan section of the beam from the upper edge to the lower edge along the height of the beam, whose dimension is $100 \mathrm{~mm} \times 3 \mathrm{~mm}$, and meanwhile, the TST3826 static strainometer is used to collect strain data. Furthermore, the midspan deflection and displacements of the two supports are measured by three dial indicators. After preloading, this test uses a step loading by using a jack and the load gradually increases at a loading rate of $2 \mathrm{kN}$. And after each loading, the corresponding load and deflection are recorded immediately when the deformation of the beam becomes stable, and the strain data are gathered through the static strainometer at the same time until the specimens are destroyed.

\section{Test Results and Analysis}

3.1. Failure Modes. According to the test results, three groups of beams from A to $\mathrm{C}$ represent some features, such as no measurable cracks, material breakage, buckling, and external drum, which means that there is no obvious damage but only reflects that the deflection increases with load. In the initial phase, the specimens remain consistent in the stage of linear elasticity. However, they gradually show a certain degree of plasticity while the load keeps increasing. Furthermore, the stiffness of beams start to decline and the deformation increases more obviously. Terminally, the loading stops until the midspan deflection of specimens reaches $70 \mathrm{~mm}\left(l_{0} / 29\right)$, and at that time, the whole beams are in the shape of "bent bow" existing large deformation. Specifically, although they can still in work, these beams eventually could not take more loading for the safety of this experiment and the loss of the application in practice caused by the very large deflection. After unloading, the instantaneous recovery of elastic deformation approximately accounts for $65 \% \sim 85 \%$ of the combined deflection. 48 hours later, there will be a further recovery of partial deformation (elastic after effect), and at last, the residual deflection takes up about $9 \% \sim 16 \%$ of the combined deflection. As can be seen from Table 2, a large part of deformations get resumed, which indicates the good ductility, good elastic deformation, and recovery ability. Table 2 illustrates the deflection data from three groups of specimens including groups A, B, and C. And the final failure modes are presented in Figure 3.

At the initial stage of loading, groups D and $\mathrm{E}$ are basically in the elastic stage. As the load increases, a limited degree of plastic deformation occurs, with the decrease of stiffness and the obvious increase of deformation, whereas other features are hidden. However, when the load is approaching the ultimate load, there is a slight cracking sound and a faint splitting sound of an adhesive layer both in the tension zone, and a few cracks appear in some defects such as the bamboo joint. Subsequently, with the increase of the load, the crack of the adhesive layer propagates rapidly in 
TABLE 1: Size table of specimens.

\begin{tabular}{|c|c|c|c|c|c|c|c|}
\hline $\begin{array}{l}\text { Specimen } \\
\text { number }\end{array}$ & $\begin{array}{l}\text { Width } \\
(\mathrm{mm})\end{array}$ & $\begin{array}{l}\text { Height } \\
(\mathrm{mm})\end{array}$ & $\begin{array}{l}\text { Length } \\
(\mathrm{mm})\end{array}$ & $\begin{array}{c}\text { Effective span } \\
(\mathrm{mm})\end{array}$ & $\begin{array}{c}\text { Width-to-height } \\
\text { ratio }\end{array}$ & $\begin{array}{c}\text { Span-to-height } \\
\text { ratio }\end{array}$ & Loading method \\
\hline A1 & 40 & 120 & 2300 & 2040 & 0.33 & 17 & $\mathrm{TL}$ \\
\hline $\mathrm{A} 2$ & 40 & 120 & 2300 & 2040 & 0.33 & 17 & $\mathrm{TL}$ \\
\hline B1 & 60 & 120 & 2300 & 2040 & 0.50 & 17 & $\mathrm{TL}$ \\
\hline B2 & 60 & 120 & 2300 & 2040 & 0.50 & 17 & $\mathrm{TL}$ \\
\hline $\mathrm{C} 1$ & 80 & 120 & 2300 & 2040 & 0.67 & 17 & $\mathrm{TL}$ \\
\hline $\mathrm{C} 2$ & 80 & 120 & 2300 & 2040 & 0.67 & 17 & $\mathrm{TL}$ \\
\hline D1 & 60 & 120 & 1150 & 1000 & 0.50 & 8.33 & $\mathrm{OL}$ \\
\hline D2 & 60 & 120 & 1150 & 1000 & 0.50 & 8.33 & $\mathrm{OL}$ \\
\hline E1 & 80 & 120 & 1150 & 1000 & 0.67 & 8.33 & $\mathrm{OL}$ \\
\hline $\mathrm{E} 2$ & 80 & 120 & 1150 & 1000 & 0.67 & 8.33 & $\mathrm{OL}$ \\
\hline
\end{tabular}

$\mathrm{TL}=$ two-point loading; $\mathrm{OL}=$ one-point loading.

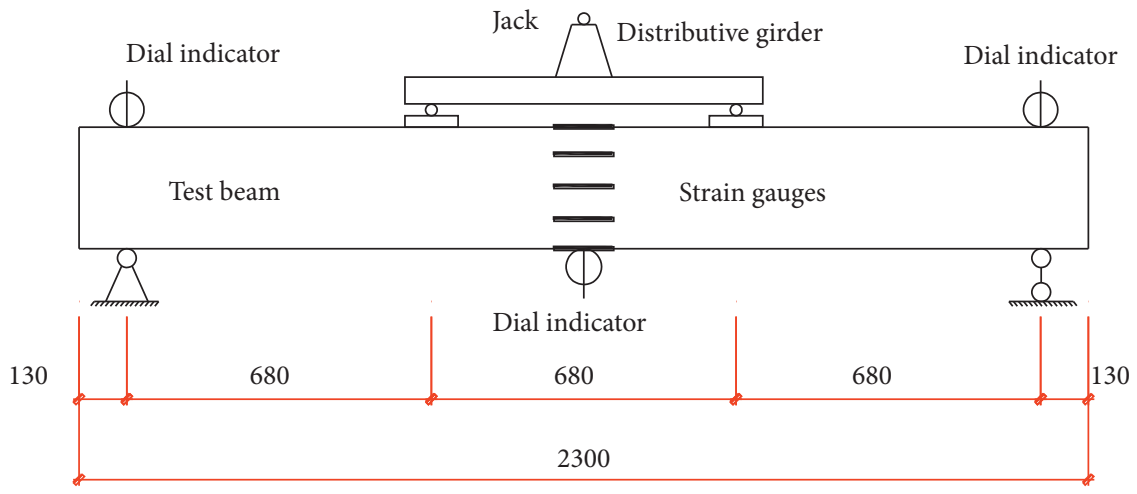

(a)

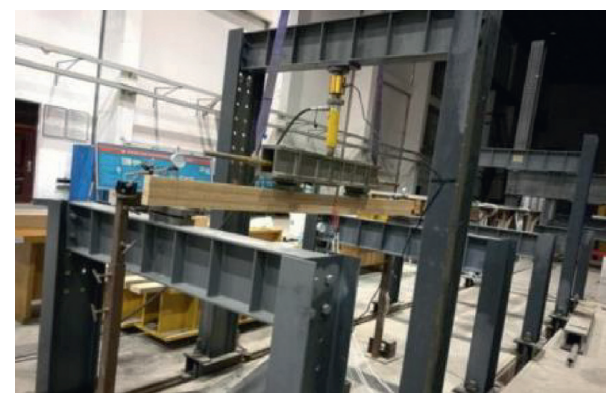

(b)

FIgURE 1: Test apparatus loading with two-point. (a) Loading schematic diagram. (b) Testing field.

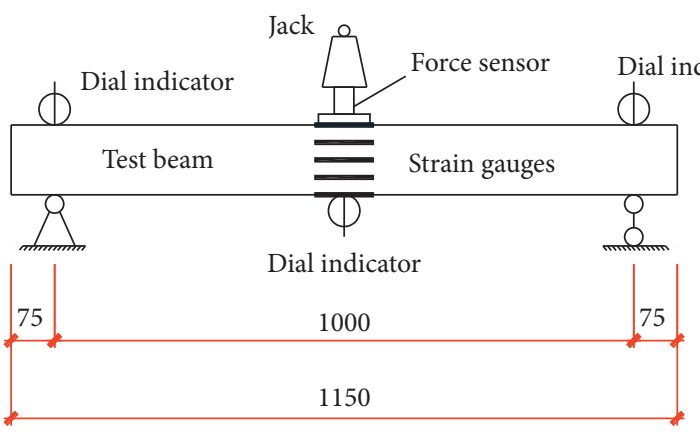

(a)

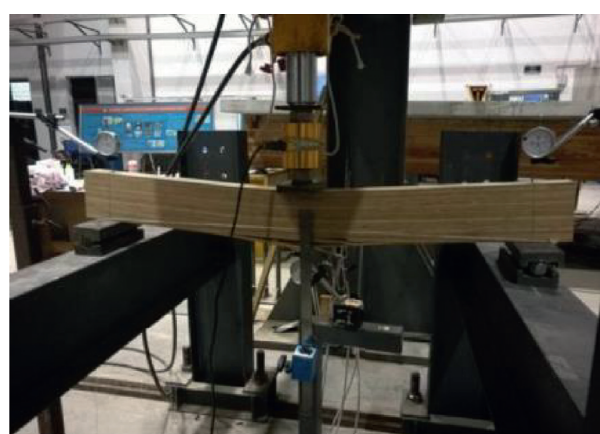

(b)

FIgURE 2: Test apparatus loading with one-point. (a) Loading schematic diagram. (b) Testing field. 
TABLE 2: Deflection parameter table.

\begin{tabular}{lccccccc}
\hline Specimen group & $f(\mathrm{~mm})$ & $f_{\mathrm{i}}(\mathrm{mm})$ & $f_{\mathrm{e}}(\mathrm{mm})$ & $f_{\mathrm{r}}(\mathrm{mm})$ & $\left(f_{\mathrm{i}} / f\right)(\%)$ & $\left(f_{\mathrm{e}} / f\right)(\%)$ & $\left(f_{\mathrm{r}} / f\right)(\%)$ \\
\hline A1 & 78.67 & 52.17 & 15.25 & 11.25 & 66.31 & 19.38 & 14.31 \\
A2 & 82.71 & 53.21 & 16.25 & 13.25 & 64.33 & 19.65 \\
B1 & 75.33 & 59.33 & 8.5 & 7.5 & 78.76 & 11.28 & 16.02 \\
B2 & 70.53 & 49.53 & 10 & 11 & 70.22 & 14.18 & 7.96 \\
C1 & 79.67 & 66.67 & 6 & 7 & 83.68 & 15.6 \\
C2 & 80.95 & 69.45 & 2.5 & 9 & 85.79 & 3.09 & 11.12 \\
\hline
\end{tabular}

$f=$ deflection; $f_{i}=$ instantaneous recovery deformation; $f_{\mathrm{e}}=$ elastic aftereffect deformation; $f_{\mathrm{r}}=$ residual deformation.

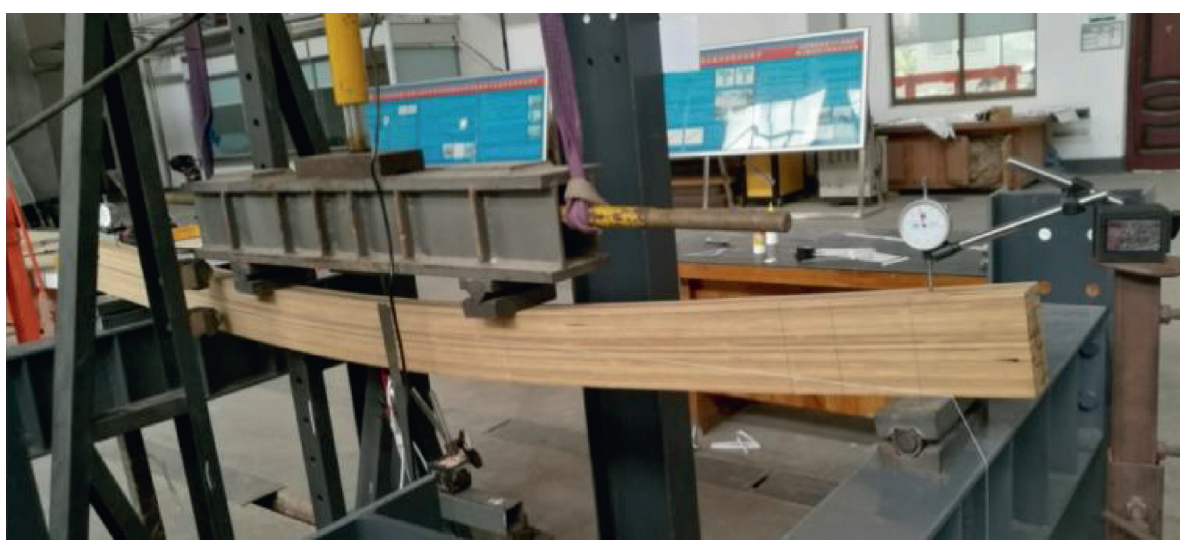

FIgURE 3: Failure modes of specimens.

the longitudinal direction. Moreover, the bamboo fibers of the tension face, which are near the loading point in the bottom of the beam, suddenly break from the bamboo joint, with clear sound. Once the outermost bamboo fibers are ruptured by tension, bamboo fibers under lateral tension will result in longitudinal splitting, and meanwhile, bearing capacity reaches the maximum level and then drops dramatically. The failure of each beam is caused by tensile, and the damage positions are all around the loading point, validating that the dangerous area is near the bottom edge loading point, where it has the maximum force. The whole failure of specimens have an imaginably short process, whose failure belongs to brittle failure. After unloading, despite of the large deflections, most of them recover obviously and even have strong recovery capacity. The final failure modes of all specimens are illustrated in Figure 4.

3.2. Load-Displacement Curve. Figure 5 shows the comparison between load-displacement curves for each specimen. It explains that the side-pressure laminated bamboo beams have experienced elastic deformation stage, elastic-plastic deformation stage, and failure stage. In addition, each specimen has conspicuous nonlinear characteristics. Also, the deflection of the beams far exceeds the maximum allowable value $8.2 \mathrm{~mm}$ $\left(l_{0} / 250\right)$ specified in the code when they are damaged. Figures 5(a) and 5(b) illustrate several groups of specimens with the same span-to-height ratio but the different width-toheight ratio. These observations indicate that an increase in the width results in an increase in the capability of the beam based on the same midspan deflection. Figure 5(a) presents that when the midspan deflection is $20 \mathrm{~mm}$, the corresponding loading of
A2, B2, and C1 are $6.48 \mathrm{kN}, 10.55 \mathrm{kN}$, and $14.11 \mathrm{kN}$, respectively. It can be seen that the corresponding load of $\mathrm{C} 1$ is $14.11 \mathrm{kN}$, which is 1.34 times that of $\mathrm{B} 2$ and 2.18 times that of A2. Likewise, the width of $\mathrm{C} 1$ is 1.33 and 2 times wider than those of B2 and A2, respectively. Figure 5(b) illustrates that when the midspan deflection is $6 \mathrm{~mm}$, the corresponding load of D2 is $21.14 \mathrm{kN}$, and that of $\mathrm{E} 1$ is $28.29 \mathrm{kN}$, which is 1.34 times higher than that of D2. Meanwhile, the width of E1 is 1.33 times higher than that of D2, indicating that the increasing capacity of side-pressure laminated bamboo beam is basically in proportion to the increase of width.

Figures 5(c) and 5(d) compare four groups of specimens with the same width-to-height ratio but the different span-toheight ratio, exhibiting that the stiffness and capacity increase with the relative decrease in the span-to-height ratio. In addition, the capabilities of groups D and $\mathrm{E}$ are 5 to 6 times higher than those of groups B and C. Comparison of Figures 5(c) and $5(d)$ represents that the groups of $B$ and $C$ beams experience far better ductility than $\mathrm{D}$ and $\mathrm{E}$. Therefore, the capacity of ductile deformation referred to $\mathrm{B}$ and $\mathrm{C}$ is stronger. These above conclusions validate that with the decline of the span-to-height ratio, the stiffness and capacity improve, whereas the ductility decreases. The promising findings of the application of sidepressure LBL beams in practice point to the considerable influence for the mechanical properties and economic efficiency of the entire structure caused by the determination of proper span-to-height ratio.

3.3. Stress Analysis for the Cross Section. Several representative beams are selected to obtain the height-strain curves of midspan section. It can be seen from Figure 6 that with the 


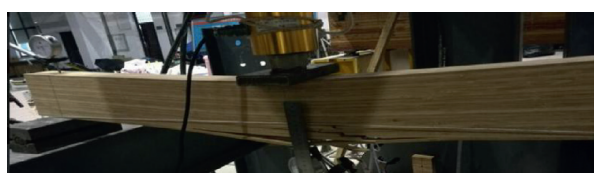

(a)

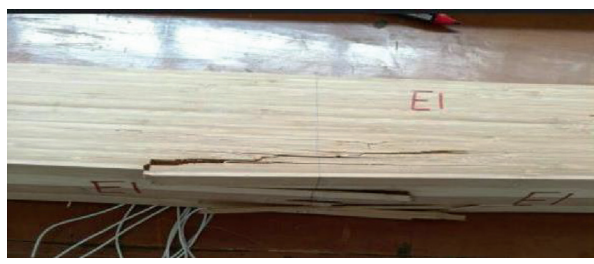

(c)

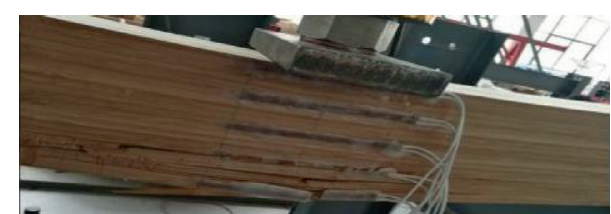

(b)

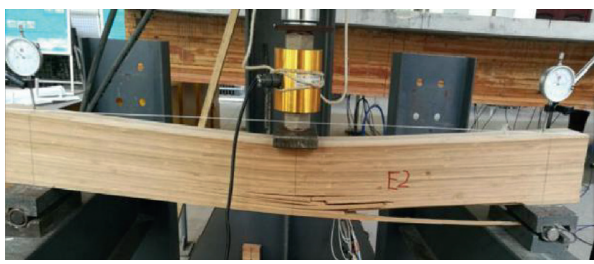

(d)

Figure 4: Failure modes of specimens. (a) Specimen D1. (b) Specimen D2. (c) Specimen E1. (d) Specimen E2.

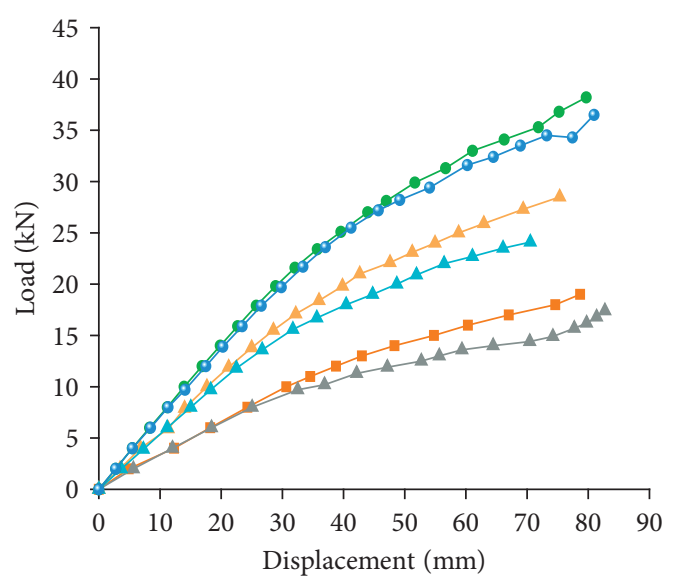

$$
\begin{array}{ll}
\rightarrow \mathrm{A} 1 & \rightarrow \mathrm{B} 2 \\
\leftarrow \mathrm{A} 2 & \rightarrow \mathrm{C} 1 \\
\leftarrow \mathrm{B} 1 & \rightarrow \mathrm{C} 2
\end{array}
$$

(a)

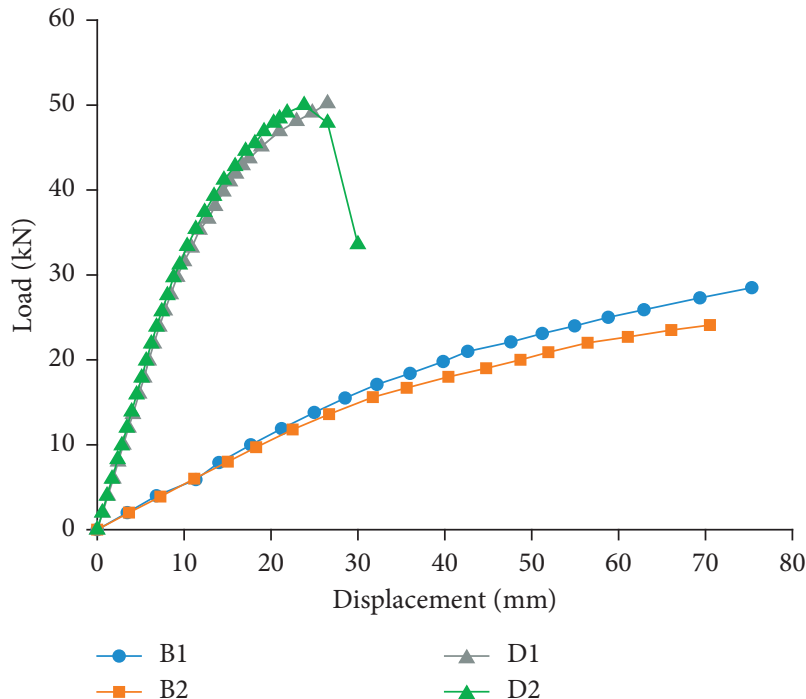

(c)

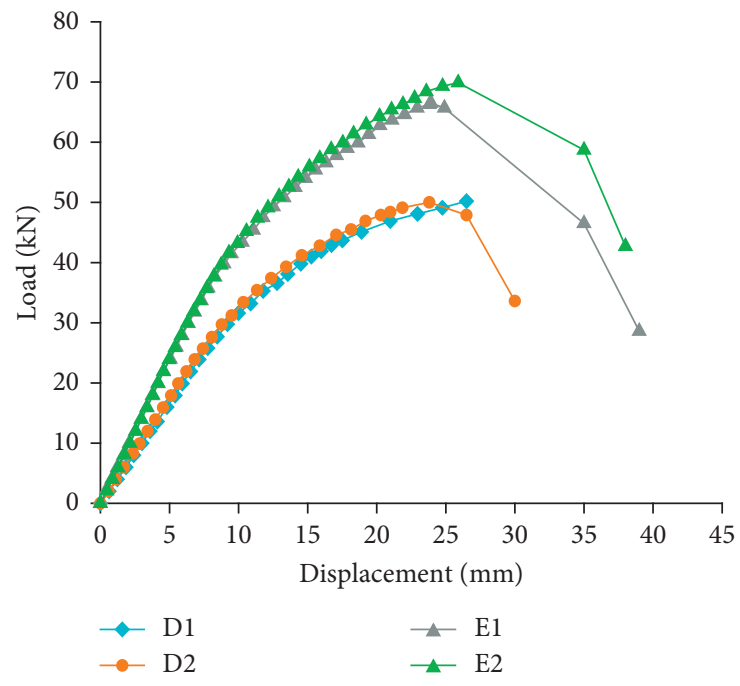

(b)

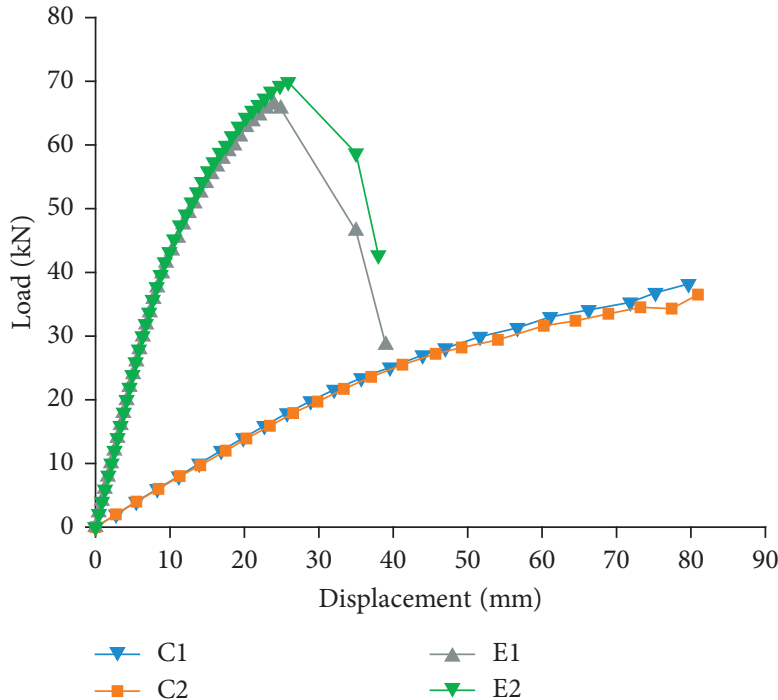

(d)

Figure 5: Comparison between load-displacement curves for each specimen. (a) Specimens A, B, and C. (b) Specimens D and E. (c) Specimens B and D. (d) Specimens C and E. 


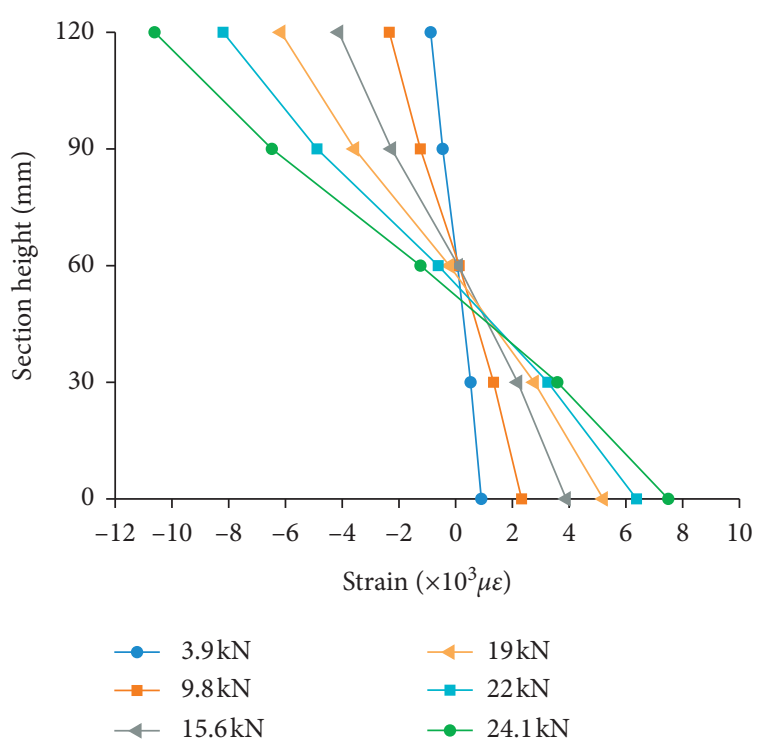

(a)

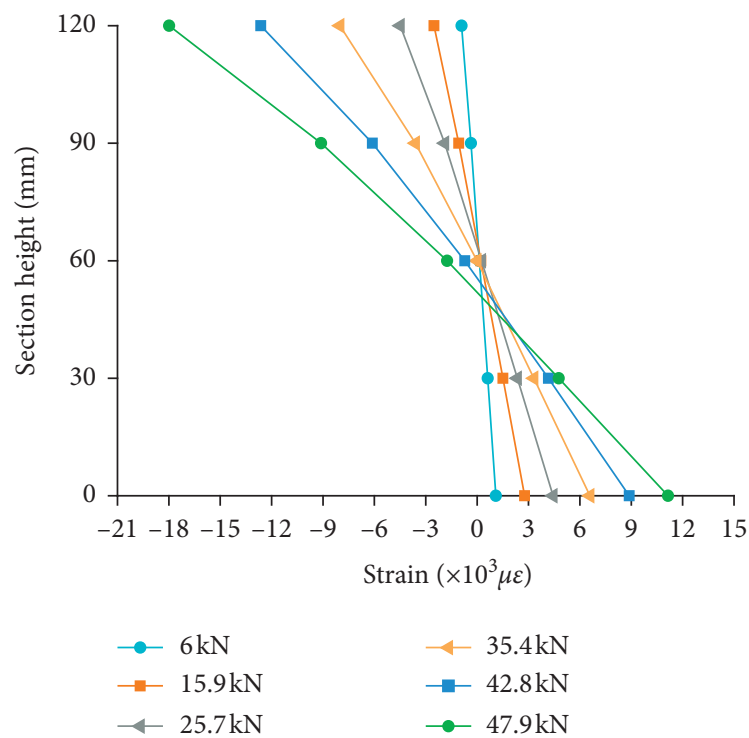

(c)

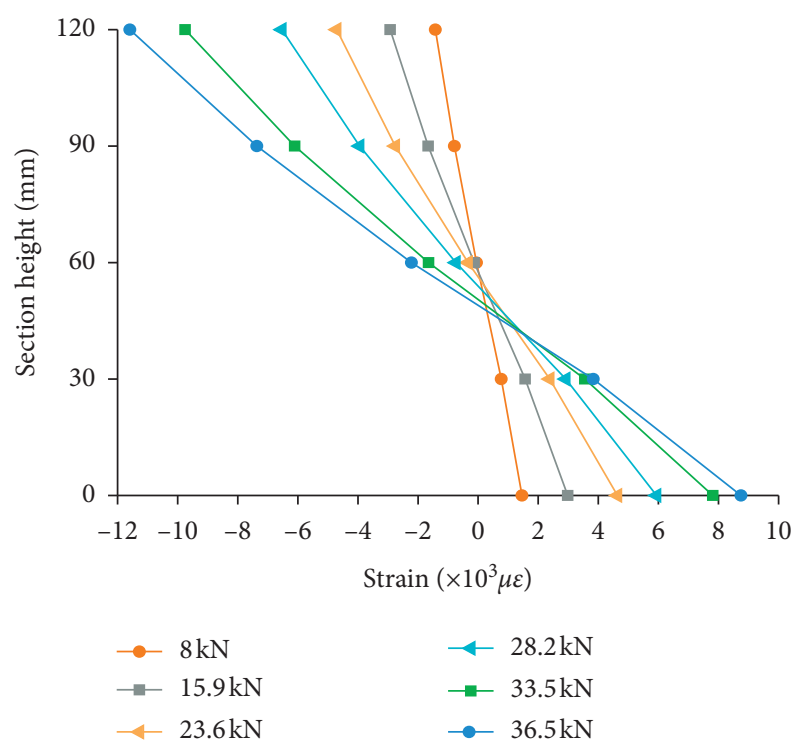

(b)

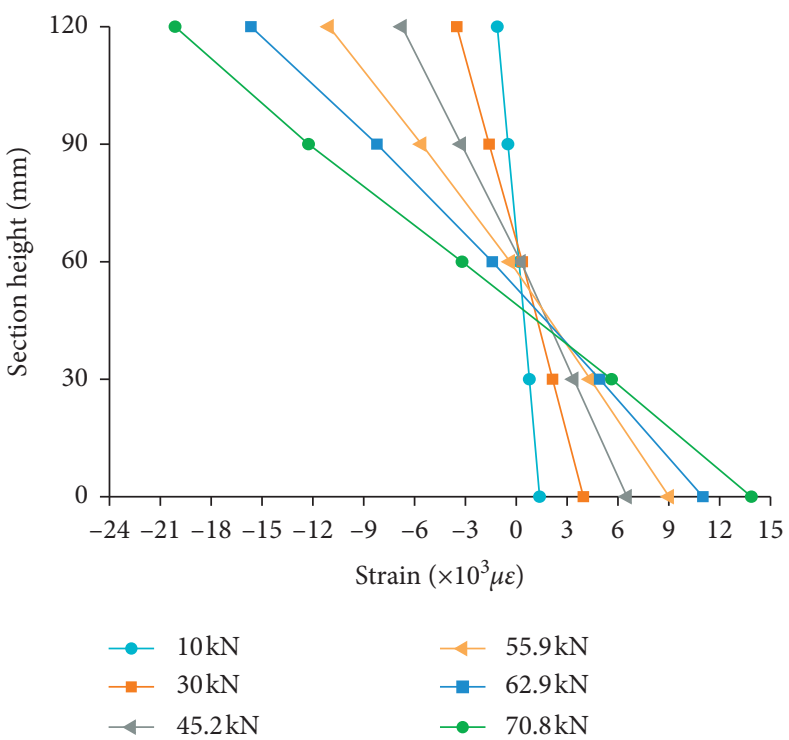

(d)

FIgURE 6: Strain distribution along the height of section at the midspan of typical specimens. (a) Specimen B2. (b) Specimen C2. (c) Specimen D2. (d) Specimen E2.

increase of load, the cross-section strain turns gradually from linear to nonlinear, the neutral axis moves downwards from the center of the beam, and the maximum distance of moving down was between 12 and $24 \mathrm{~mm}$. Moreover, the top compressive strain of the cross section is bigger than bottom tensile strain. However, the average strain across the midspan cross section of the beam is basically linear throughout the loading process, following the plane section assumption. Thus, plane section assumption could be used in the calculation during the design process of LBL beams. The downward neutral axis is caused by the inequality of tensile and compressive strength. That is because when the tensile strength is bigger than compressive strength, the downward neutral axis is needed in order to decrease the height of the tension zone, as well as to increase the height of the compression zone, and finally to strike a balance among the cross-section internal forces.

3.4. Test Results. The experimental results of specimens are shown in Table 3. As can be seen in Table 3, the proportional limit load of specimens accounts for about half of the ultimate load. Meanwhile, the deflection at the proportional limit and the deflection at the ultimate load are approximately $l_{0} / 80 \sim l_{0} / 135$ and $l_{0} / 30 \sim l_{0} / 40$, respectively. However, as referred to the current reference, standard for design of timber structures (GB50005) [28], the maximum midspan deflection of the beams are not allowed to exceed the allowable value $l_{0} / 250$ when in normal service stage. The deflection of the beams has already far exceeded the 
TABLE 3: Main test results of specimens.

\begin{tabular}{|c|c|c|c|c|c|c|c|c|c|}
\hline \multirow{2}{*}{ Specimen } & \multicolumn{4}{|c|}{ Proportional elastic limit } & \multirow{2}{*}{$F_{1 / 250}(\mathrm{kN})$} & \multicolumn{4}{|c|}{ Bearing capacity } \\
\hline & $\omega_{\mathrm{p}}(\mathrm{mm})$ & $F_{\mathrm{p}}(\mathrm{kN})$ & $f_{\mathrm{p}}(\mathrm{MPa})$ & $\bar{f}_{\mathrm{p}}(\mathrm{MPa})$ & & $\omega_{\mathrm{m}}(\mathrm{mm})$ & $F_{\mathrm{m}}(\mathrm{kN})$ & $f_{\mathrm{m}}(\mathrm{MPa})$ & $\bar{f}_{\mathrm{m}}(\mathrm{MPa})$ \\
\hline A1 & 26.83 & 8.80 & 31.17 & 29.74 & 3.15 & 70.0 & 17.40 & 61.00 & 55.82 \\
\hline A2 & 25.05 & 8.00 & 28.30 & 29.74 & 3.15 & 70.0 & 14.30 & 50.64 & 55.82 \\
\hline B1 & 24.99 & 13.80 & 32.60 & 31.50 & 4.80 & 70.0 & 27.40 & 64.70 & 60.80 \\
\hline B2 & 25.01 & 12.88 & 30.40 & 31.50 & 4.80 & 70.0 & 24.10 & 56.90 & 60.80 \\
\hline $\mathrm{C} 1$ & 25.73 & 17.90 & 31.70 & 31.70 & 6.50 & 70.0 & 34.90 & 61.80 & 60.90 \\
\hline $\mathrm{C} 2$ & 26.57 & 17.90 & 31.70 & 31.70 & 6.50 & 70.0 & 33.90 & 60.00 & 60.90 \\
\hline D1 & 7.77 & 25.80 & 44.79 & 44.71 & 13.24 & 26.50 & 50.20 & 87.15 & 86.98 \\
\hline D2 & 7.74 & 25.70 & 44.62 & 44.71 & 14.02 & 23.81 & 50.00 & 86.81 & 86.98 \\
\hline E1 & 7.31 & 33.70 & 43.88 & 43.88 & 19.10 & 23.94 & 66.50 & 86.59 & 88.81 \\
\hline E2 & 7.21 & 33.70 & 43.88 & 43.88 & 19.07 & 25.89 & 69.90 & 91.02 & 88.81 \\
\hline
\end{tabular}

$F_{\mathrm{p}}=$ ultimate elastic proportional load; $\omega_{\mathrm{p}}=$ midspan deflection of the beam corresponding to $F_{\mathrm{p}} ; f_{\mathrm{p}}=$ flexural strength corresponding to $F_{\mathrm{p}} ; F_{1 / 250}=$ load corresponding to 1/250 midspan deflection; $F_{\mathrm{m}}=$ ultimate load; $\omega_{\mathrm{m}}=$ midspan deflection of the beam corresponding to $F_{\mathrm{m}} ; f_{\mathrm{m}}=$ ultimate flexural strength.

maximum allowable value specified in the code when specimens are under the proportional limit load. Also, when the midspan deflection of the beams ultimately reaches the $l_{0} / 250$, the corresponding load is about $18 \% \sim 28 \%$ of the ultimate load, which concludes that the capacity of specimens is far yet to come. Therefore, during the design process of side-pressure laminated bamboo beams, it is worth nothing that the stiffness or deflection is regarded as the control index, instead of bearing capacity. In addition, the deflection of specimens under the ultimate load is about 3 times higher than that of specimens under proportional limit load, which leads to the longer nonlinear stage of the loaddeflection curve.

Weibull [29] presented periodic brittle fracture, which proved size effect of strength. Madsen and Buchanan [30] investigated with numerous experimental studies and found that the size effect of flexural strength was an important issue. Particularly, the effect of length was more significant than that of height. Bohannan [31] applied the periodic brittle fracture proposed by Weibull to explore the effect of component size on the flexural strength. Furthermore, the study represented that the flexural strength was in inverse proportion to the one ninth power of height when the spanto-height ratio was constant. And it was also considered that the bending strength was not affected by the width. In Table 3, through the comparison of the groups from A to C and the groups from $\mathrm{D}$ to $\mathrm{E}$, all specimens have flexural strength inclusive of the flexural strength at the proportional limit and the ultimate flexural strength, but the flexural strength at the proportional limit for $\mathrm{A}, \mathrm{B}$, and $\mathrm{C}$ is around $30 \mathrm{MPa}$ while that for $\mathrm{D}$ and $\mathrm{E}$ is about $44 \mathrm{MPa}$, which is approximately 1.467 times higher than that of the first three groups. Meanwhile, the ultimate flexural strength of groups $\mathrm{D}$ and $\mathrm{E}$ is about $88 \mathrm{MPa}$, which is 1.467 times higher than that of the first three groups. One reason is that the effect of size effect causes the difference between the long members and short members, which are corresponding to groups A to $\mathrm{C}$ and groups D to E, respectively. Although the width of specimens changes, the flexural strength is basically the same, validating that there is no influence of width upon the flexural strength. Different from the width, when the span rises from $1000 \mathrm{~mm}$ to $2040 \mathrm{~mm}$, with an increase of $104 \%$, the flexural strength at the proportional limit degenerates by $47 \%$, indicating the remarkable influence of size effect. According to the experimental results in Table 3, with an increase of size, the probability of defects in members also increases, which leads to the higher failure probability and the decline of flexural strength. Overall, the findings of this study are basically anastomotic with the conclusions of the above scholars.

\section{Calculation of Flexural Capacity}

4.1. Calculation Methods of Flexural Capacity. With the attempt to deduce the calculation formulas of ultimate flexural capacity for side-pressure laminated bamboo lumber beams, there are some assumptions adopted in the derivative process:

(1) The cross-section strain of the side-pressure laminated bamboo beams basically conforms to the plane cross-section assumption, and during the bending process, no section warping occurs.

(2) The elastic modulus for both compression and tension is equal [23].

(3) The tension zone of the side-pressure laminated bamboo beams experiences a complete linear elastic stage, and the outermost fiber of the tension zone reaches the ultimate tensile strength. Moreover, the compression zone is in the ideal elastic-plastic state, and the stress in the plastic compression zone is assumed to maintain the compressive proportional limit strength.

When determining the material strength of specimens, the intensity of the substandard specimen needs reduction. In this paper, after the size effect of members, the existing defeats of specimens, the material strength variations, and other comprehensive factors are considered, and the strength reduction factor is finally determined, which is 0.89 [32].

According to the basic assumption, the stress-strain distribution of failure section of side-pressure LBL beams in the ultimate limit state is presented in Figure 7: 


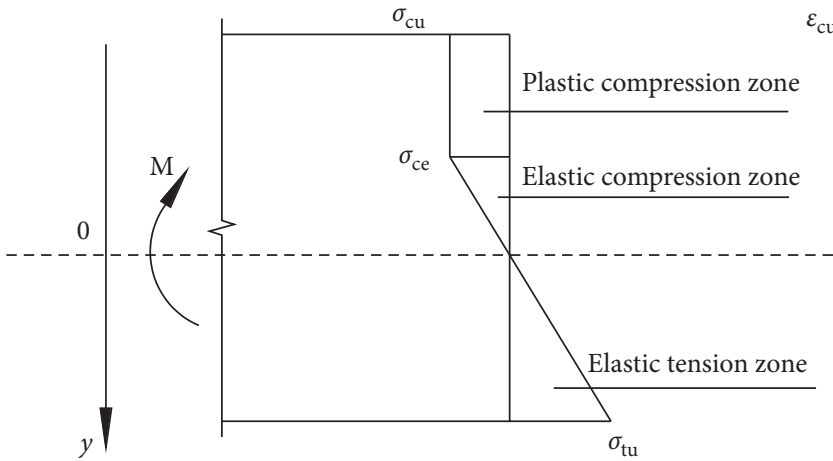

(a)

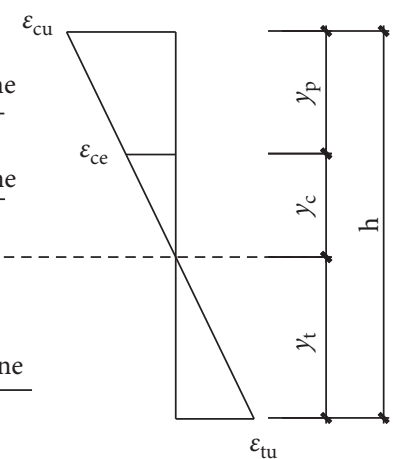

(b)

Figure 7: Diagrams of the stress and strain over the moment section. (a) Stress diagram. (b) Strain diagram.

$$
\sigma(y)= \begin{cases}-E_{\mathrm{c}} k_{\mathrm{p}} y_{\mathrm{c}}, & -\left(y_{\mathrm{c}}+y_{\mathrm{p}}\right) \leq y \leq-y_{\mathrm{c}}, \\ E_{\mathrm{c}} k_{\mathrm{p}} y, & -y_{\mathrm{c}} \leq y \leq 0, \\ E_{\mathrm{t}} k_{\mathrm{p}} y, & 0 \leq y \leq y_{\mathrm{t}} .\end{cases}
$$

Note that $E_{\mathrm{c}}$ and $E_{\mathrm{t}}$, respectively, represent the compressive elastic modulus and tensile elastic modulus, and because they are equal according to the assumption, in the process of analysis, $E_{\mathrm{c}}$ is uniformly represented by $E_{\mathrm{t}}$. Additionally, $K_{\mathrm{p}}$ represents the cross-section curvature.

On the basis of the plane cross-section assumption, the relationship between the height of tension and elastic compression zone can be obtained as follows:

$$
\frac{y_{\mathrm{t}}}{y_{\mathrm{c}}}=\frac{\varepsilon_{\mathrm{tu}}}{\varepsilon_{\mathrm{ce}}}=-\frac{E_{\mathrm{t}} \sigma_{\mathrm{tu}}}{E_{\mathrm{t}} \sigma_{\mathrm{ce}}}=-\frac{\sigma_{\mathrm{tu}}}{\sigma_{\mathrm{ce}}} .
$$

The equilibrium condition of normal stress for the cross section of the beams is as follows:

$$
b \int_{-\left(y_{\mathrm{p}}+y_{\mathrm{c}}\right)}^{y_{\mathrm{t}}} \sigma(y) \mathrm{d} y=0 \text {. }
$$

Substitute equation (1) into equation (3) to obtain

$$
\int_{-\left(y_{\mathrm{p}}+y_{\mathrm{c}}\right)}^{-y_{\mathrm{c}}}\left(-E_{\mathrm{t}} k_{\mathrm{p}} y_{\mathrm{c}}\right) \mathrm{d} y+\int_{-y_{\mathrm{c}}}^{0} E_{\mathrm{t}} k_{\mathrm{p}} y \mathrm{~d} y+\int_{0}^{y_{\mathrm{t}}} E_{\mathrm{t}} k_{\mathrm{p}} y \mathrm{~d} y=0 .
$$

Considering the relationships of the height of the compression zone,

$$
y_{\mathrm{t}}+y_{\mathrm{c}}+y_{\mathrm{p}}=h
$$

Then, integrate equation (4) to obtain

$$
-E_{\mathrm{t}} k_{\mathrm{p}} y_{\mathrm{c}} y_{\mathrm{p}}-\frac{1}{2} E_{\mathrm{t}} k_{\mathrm{p}} y_{\mathrm{c}}^{2}+\frac{1}{2} E_{\mathrm{t}} k_{\mathrm{p}} y_{\mathrm{t}}^{2}=0
$$

So,

$$
\sigma_{\mathrm{ce}} y_{\mathrm{p}}+\frac{1}{2} \sigma_{\mathrm{ce}} y_{\mathrm{c}}+\frac{1}{2} \sigma_{\mathrm{tu}} y_{\mathrm{t}}=0
$$

Based on the above equation, the height of the tension zone, as well as the height of elastic and plastic compression zones, can be deduced:

$$
\begin{aligned}
& y_{\mathrm{t}}=\frac{2 \sigma_{\mathrm{tu}} \sigma_{\mathrm{ce}}}{\sigma_{\mathrm{ce}}^{2}+2 \sigma_{\mathrm{tu}} \sigma_{\mathrm{ce}}+\sigma_{\mathrm{tu}}^{2}} h, \\
& y_{\mathrm{c}}=\frac{2 \sigma_{\mathrm{ce}}^{2}}{\sigma_{\mathrm{ce}}^{2}+2 \sigma_{\mathrm{tu}} \sigma_{\mathrm{ce}}+\sigma_{\mathrm{tu}}^{2}} h, \\
& y_{\mathrm{p}}=\frac{\sigma_{\mathrm{tu}}^{2}-\sigma_{\mathrm{ce}}^{2}}{\sigma_{\mathrm{ce}}^{2}+2 \sigma_{\mathrm{tu}} \sigma_{\mathrm{ce}}+\sigma_{\mathrm{tu}}^{2}} h .
\end{aligned}
$$

The ultimate bending moment for the LBL beams can be calculated by the following equation:

$$
M=b \int_{-\left(y_{p}+y_{c}\right)}^{y_{t}} \sigma(y) y \mathrm{~d} y .
$$

Substitute equation (1) into equation (9) to obtain

$$
\begin{aligned}
M= & b\left[\int_{-\left(y_{\mathrm{c}}+y_{\mathrm{p}}\right)}^{-y_{\mathrm{c}}}\left(-E_{\mathrm{t}} K_{\mathrm{p}} y_{\mathrm{c}}\right) y \mathrm{~d} y+\int_{-y_{\mathrm{c}}}^{0} E_{\mathrm{t}} K_{\mathrm{P}} y^{2} \mathrm{~d} y\right. \\
& \left.+\int_{0}^{y_{t}} E_{\mathrm{t}} K_{\mathrm{P}} y^{2} \mathrm{~d} y\right] .
\end{aligned}
$$

Then, integrate equation (10) to obtain

$$
M=b\left(\frac{1}{2} E_{\mathrm{t}} K_{\mathrm{p}} y_{\mathrm{c}} y_{\mathrm{p}}^{2}+E_{\mathrm{t}} K_{\mathrm{p}} y_{\mathrm{c}}^{2} y_{\mathrm{p}}+\frac{1}{3} E_{\mathrm{t}} K_{\mathrm{p}} y_{\mathrm{c}}^{3}+\frac{1}{3} E_{\mathrm{t}} K_{\mathrm{p}} y_{\mathrm{t}}^{3}\right)
$$

Substitute equation (1) into equation (11) to obtain

$$
M=b\left(\frac{1}{2} \sigma_{\mathrm{ce}} y_{\mathrm{p}}^{2}+\sigma_{\mathrm{ce}} y_{\mathrm{c}} y_{\mathrm{p}}+\frac{1}{3} \sigma_{\mathrm{ce}} y_{\mathrm{c}}^{2}+\frac{1}{3} \sigma_{\mathrm{tu}} y_{\mathrm{t}}^{2}\right)
$$

4.2. Experimental Verification. According to the experimental results, substitute the ultimate tensile strength and the compressive strength at proportional limit into equation (8) to obtain the stress distribution of failure section in various heights, namely, $y_{\mathrm{t}}, y_{\mathrm{c}}$, and $y_{\mathrm{p}}$, and then calculate the ultimate bending moment of cross section by equation (12). Subsequently, under the ultimate state of bearing capacity, calculate the maximum load through the calculation formula $M=(F / 2) l_{0}$ (note that $l_{0}$ represents the value of the effective span. It is expected that the half and the one-third of 
TABLE 4: Comparing the results of tests to those of calculations.

\begin{tabular}{lcccc}
\hline \multirow{2}{*}{ Specimen } & \multicolumn{2}{c}{ Maximum load $(\mathrm{kN})$} & Difference value $(\mathrm{kN})$ & Relative error $(\%)$ \\
\hline D1 & Experimental value & Calculated value & -3.67 & 7.31 \\
D2 & 50.2 & 46.53 & -3.47 & 6.94 \\
E1 & 50.0 & 46.53 & -4.46 & 6.71 \\
E2 & 66.5 & 62.04 & -7.86 & 11.2 \\
\hline
\end{tabular}

the effective span are, respectively, applied to the one-point loading and two-point loading).

Furthermore, in the condition that the deflection of the A, B, and C groups of beams is too large to load to failure and the test value has no access to reach the ultimate load. It is not exhibited in Table 4 because the calculated value is greater than the experimental value. However, as can be seen in Table 4, the calculated value and the experimental value of $\mathrm{D}$ and $\mathrm{E}$ groups of beams are both approximately equal, indicating the feasibility of the calculation method of flexural capacity for the side-pressure LBL beams.

\section{Conclusion}

(1) Under the loading, the side-pressure laminated bamboo beams have experienced elastic deformation stage, elastic-plastic deformation stage, and failure stage. In addition, the proportional limit load of specimens accounts for about half of the ultimate load.

(2) With the decline of the span-to-height ratio, the stiffness and capacity improve, whereas the ductility decreases, and vice versa. Therefore, the determination of proper span-to-height ratio is needed in the actual project.

(3) The average strain across the midspan cross section of the beam is basically linear throughout the loading process, following the plane cross-section assumption. Meanwhile, with the increase of load, the neutral axis moves downward from the center of the beam to the tension zone.

(4) The deflection at the proportional limit and the deflection at the ultimate load are approximately $l_{0} /$ $80 \sim l_{0} / 135$ and $l_{0} / 30 \sim l_{0} / 40$, respectively, and both far exceed the maximum allowable value specified in the code. Hence, it is worth nothing that the stiffness or deflection is regarded as the control index, instead of bearing capacity.

(5) On the basis of the nonlinear deformation of the simply supported beams of side-pressure laminated bamboo, the proposal of the calculation method for the flexural bearing capacity could be given the due consideration, and finally, the calculations give good agreement with the test results.

\section{Data Availability}

Some data used to support the findings of this study are included within the article. All datasets generated during the current study are not publicly available because the data also form part of an ongoing study but are available from the corresponding author on reasonable request.

\section{Disclosure}

The opinions and findings in this paper are those of the authors and do not represent those of the sponsors.

\section{Conflicts of Interest}

The authors declare that they have no conflicts of interest.

\section{Authors' Contributions}

Jing Lei and Bowang Chen contributed equally.

\section{Acknowledgments}

This research was financially supported by Innovation and Entrepreneurship Technology Investment Project of Hunan Province of China (2019GK5087) and Science and Technology Planning Project of Changsha City (kq1901135).

\section{References}

[1] H.-t. Li, J.-w. Su, Q.-s. Zhang, A. J. Deeks, and D. Hui, "Mechanical performance of laminated bamboo column under axial compression," Composites Part B: Engineering, vol. 79, pp. 374-382, 2015.

[2] H. T. Li, Q. S. Zhang, G. Wu, X. H. Xiong, and Y. J. Li, "A review on development of laminated bamboo lumber," Journal of Forestry Engineering, vol. 1, pp. 10-16, 2016.

[3] Z. Huang, Z. Chen, D. Huang, and A. Zhou, "The ultimate load-carrying capacity and deformation of laminated bamboo hollow decks: experimental investigation and inelastic analysis," Construction and Building Materials, vol. 117, pp. 190-197, 2016.

[4] B. Chen, T. Zhou, L. Li, X. Zhang, and H. T. Li, "Study of a three-phase bridgeless flyback PFC converter," International Journal of Electronics and Electrical Engineering, vol. 40, no. 5, pp. 121-125, 2016.

[5] Z. K. Liu, H. W. Yu, C. J. Luo, and Z. J. Lv, "Study on the production technology of high moisture content wood (bamboo) integrated timber," China Forest Products Industry, vol. 43, no. 4, pp. 12-15, 2016.

[6] T. P. S. Reynolds, B. Sharma, E. Serrano, P. Gustafsson, and M. H. Ramage, "Fracture of laminated bamboo and the influence of preservative treatments," Composites Part B: Engineering, vol. 174, no. 1, Article ID 107017, 2019.

[7] A. Chow, M. H. Ramage, and D. U. Shah, "Optimising ply orientation in structural laminated bamboo," Construction and Building Materials, vol. 212, pp. 541-548, 2019. 
[8] H. T. Li, Q. S. Zhang, and G. Wu, "Stress-strain model under compression for side pressure laminated bamboo," Journal of Southeast University (Natural Science Edition), vol. 45, no. 6, pp. 1130-1134, 2015.

[9] J. W. Su, H. T. Li, P. Yang, Q. S. Zhang, and G. Chen, "Mechanical performance study on laminated bamboo lumber column pier under axial compression," China Forestry Science and Technology, vol. 29, no. 4, pp. 45-49, 2015.

[10] H.-t. Li, G. Chen, Q. Zhang, M. Ashraf, B. Xu, and Y. Li, "Mechanical properties of laminated bamboo lumber column under radial eccentric compression," Construction and Building Materials, vol. 121, pp. 644-652, 2016.

[11] H. T. Li, G. Wu, Q. S. Zhang, and G. Chen, "Experimental study on side pressure LBL under tangential eccentric compression," Journal of Hunan University (Natural Science Edition), vol. 43, no. 5, pp. 90-96, 2016.

[12] H.-t. Li, G. Wu, Q.-s. Zhang, and J.-W. Su, "Mechanical evaluation for laminated bamboo lumber along two eccentric compression directions," Journal of Wood Science, vol. 62, no. 6, pp. 503-517, 2016.

[13] I. M. Sulastiningsih and B. Nurwati, "Physical and mechanical properties of laminated bamboo board," Journal of Tropical Forest Science, vol. 21, no. 3, pp. 246-251, 2009.

[14] C.-H. Lee, M.-J. Chung, C.-H. Lin, and T.-H. Yang, "Effects of layered structure on the physical and mechanical properties of laminated moso bamboo (Phyllosachys edulis) flooring," Construction and Building Materials, vol. 28, no. 1, pp. 31-35, 2012.

[15] O. Sulaiman, R. Hashim, R. Wahab, Z. A. Ismail, H. W. Samsi, and A. Mohamed, "Evaluation of shear strength of oil treated laminated bamboo," Bioresource Technology, vol. 97, no. 18, pp. 2466-2469, 2006.

[16] J. B. Paes, A. K. Freire de Oliveira, E. de Oliveira, and C. R. de Lima, "Physical-mechanical characterization of the glue laminated bamboo (Dendrocalamus giganteus)," Ciencia Florestal, vol. 19, pp. 41-51, 2009.

[17] J. F. Correal and F. Ramirez, "Adhesive bond performance in glue line shear and bending for glued laminated guadua bamboo," Journal of Tropical Forest Science, vol. 22, pp. 433-439, 2010.

[18] K. Rassiah, M. M. H. Megat Ahmad, and A. Ali, "Mechanical properties of laminated bamboo strips from Gigantochloa scortechinii/polyester composites," Materials \& Design, vol. 57, pp. 551-559, 2014.

[19] Y. Wei, Sh X. Jiang, Q. F. Lv, Q. Sh. Zhang, L. B. Wang, and Zh T. Lv, "Flexural performance of glued laminated bamboo beams," Advanced Materials Research, vol. 168-170, pp. 1700-1703, 2011.

[20] A. Sinha, D. Way, and S. Mlasko, "Structural performance of glued laminated bamboo beams," Journal of Structural Engineering, vol. 140, no. 1, Article ID 04013021, 2014.

[21] D. M. d. Lima, M. M. Amorim, H. C. Lima Júnior, N. P. Barbosa, and F. L. Wilrich, "Avaliação do comportamento de vigas de bambu laminado colado submetidas à flexão," Ambiente Construído, vol. 14, no. 1, pp. 15-27, 2014.

[22] B. Sharma, A. Gatóo, and M. H. Ramage, "Effect of processing methods on the mechanical properties of engineered bamboo," Construction and Building Materials, vol. 83, pp. 95-101, 2015.

[23] H. T. Li, J. W. Su, Q. S. Zhang, and G. Chen, "Experimental study on mechanical performance of side pressure laminated bamboo beam," Journal of Building Structures, vol. 36, no. 3, pp. 121-126, 2015.
[24] C. S. Verma, R. Purohit, R. S. Rana, and H. Mohit, "Mechanical properties of bamboo laminates with other composites," Materials Today: Proceedings, vol. 4, no. 2, pp. 3380-3386, 2017.

[25] H. Li, G. Wu, Q. Zhang, A. J. Deeks, and J. Su, "Ultimate bending capacity evaluation of laminated bamboo lumber beams," Construction and Building Materials, vol. 160, pp. $365-375,2018$.

[26] ASTM D198-02, Standard Test Methods for Static Tests of Lumber in Structural Sizes, ASTM International, West Conshohocken, PA, USA, 2002.

[27] G. B. Mohurd, 50329-2012 Standard for Test Methods of Timber Structures, China Building Industry Press, Beijing, China, 2012.

[28] G. B. Mohurd, 50005-2017 Standard for Design of Timber Structures, China Building Industry Press, Beijing, China, 2017.

[29] W. Weibull, "A statistical theory of the strength of materials," in Proceedings of the Royal Swedish Institute for Engineering Research, vol. 151, p. 1, Stockholm, Sweden, 1939.

[30] B. Madsen and A. H. Buchanan, "Size effects in timber explained by a modified weakest link theory," Canadian Journal of Civil Engineering, vol. 13, no. 2, pp. 218-232, 1986.

[31] B. Bohannan, "Effect of size on bending strength of wood members," in United States Forest Service Research Paper FPL 56 USDA Forest Service. Forest Products Laboratory, Madison, Wisconsin, 1966.

[32] Manual for Design of Timber Structures, China Building Industry Press, Beijing, China, 2005. 